\title{
The Research and Analysis on Failure Distribution Model of Diesel Engine Component Parts
}

\author{
Shaokun Wang, Yamei Zhou, Qiang Zhang, Shuai Yang, Guanfeng Wang, Xiang Li \\ School of mechanical engineering, Shandong University, Key Laboratory of High-efficiency and Clean Mechanical Manufacture (Shandong \\ University), Ministry of Education, Jinan 250061, China
}

\begin{abstract}
Reliability research not only provides the direction of quality improvement for new product research and development, but also helps to get the product failure distribution model, so as to ensure the logistics organization to improve the service level. According to the reliability data from the database of research group, we analyzed the rule of failure distribution of high frequency fault component (fuel injection pump) and built a Weibull model. The parameters of the model are estimated and solved by using the uniform linear method and the least square method. After solving the model, the density function curves and the failure rate curves are drawn, and then the model of the demand forecasting of spare parts based on the failure distribution is obtained.
\end{abstract}

\section{Introduction}

At present, there is still a gap of the overall quality level of the engine between our country and the developed countries. Not only the average life expectancy is lower than abroad, and there will be various faults during operation. This phenomenon requires to improving the quality level and improving the quality of the engine. Reliability research not only provides the direction of quality improvement for new product research and development, but also helps to get the product failure distribution model, so as to ensure the logistics organization to improve the service level. In the reliability research, we need to analyze the failure law of products, in order to carry out reliability evaluation. The introduction of a life distribution model to fit the existing data is necessary.

Since Weibull distribution model was invented later, because the good life estimation results, it become a most widely used model in the field of reliability research quickly [1]. Abernethy summarizes a variety of commonly used parameters estimation model which is related to the Weibull distribution, method and application in product life distribution, and gives a lot of data analysis examples [2]. In terms of estimation and test method of life distribution, in addition to the traditional methods, people also established other parameter estimation methods, and introduced the research on genetic algorithm [3]. In order to study the warranty period of the new product, Mann assumed that the product failure data following the Weibull distribution, and proposed a method for estimating the reliability of the product to determine the warranty period of the new product [4].

\section{Establishment and analysis of failure distribution model for fuel injection pump}

Failure probability is a function of time $t$, which is a random variable.It is defined as:

$$
F(t)=P\{T \leq t\} \quad t \geq 0
$$

$\mathrm{F}(\mathrm{t})$ is a failure distribution function, as known as the degree of unreliability. It is expressed the probability in the time $t$ or before time $t$. The degree of reliability $R(t)$ is the probability which is the product being completed in time t.

Probability density function of the Weibull distribution

$$
f(t)=\frac{m}{\eta}\left(\frac{t-\gamma}{\eta}\right)^{m-1} \mathrm{e}^{-\left(\frac{t-\gamma}{\eta}\right)^{\mathrm{m}}}
$$

where $m$ is shape parameter, $\eta$ is scale parameter, $Y$ is position parameter.

Failure probability function

$$
F(t)=\int_{\infty}^{t} f(x) d x=1-\exp \left[-\left(\frac{t-\gamma}{\eta}\right)^{m}\right]
$$

Failure rate function

$$
\lambda(t)=\frac{m}{\eta}\left(\frac{t-\gamma}{\eta}\right)^{m-1}
$$

Reliability function 


$$
R(t)=1-F(t)=\exp \left[-\left(\frac{t-\gamma}{\eta}\right)^{m}\right]
$$

The failure distribution model of the fuel injection pump is established by using the uniform linear method to estimate the parameters.

For three-parameters Weibull model, $\mathrm{t}$ is product life, $\mathrm{F}(\mathrm{t})$ is the cumulative failure probability distribution function.

$$
F(t)=\int_{\infty}^{t} f(x) d x=1-\exp \left[-{\frac{(t-\gamma)}{t_{0}}}^{m}\right]
$$

where $t_{0}=\eta^{\mathrm{m}}$. $\mathrm{m}$ is shape parameter $\mathrm{m}>0, \mathrm{Y}$ is position parameter $\mathrm{Y}>0, t_{0}$ is scale parameter

The Weibull distribution linear processing

$$
Y=\ln \ln \left[\frac{1}{1-F(t)}\right]
$$

Turn into $Y=b X+a$

where $X=\ln (t-\gamma)$

Two-parameters Weibull distribution

$$
F(t)=\int_{\infty}^{t} f(x) d x=1-\exp \left[-{\frac{(t)}{t_{0}}}^{m}\right]
$$

The sample data from small to large array, then get a set of data, $\mathrm{t} 1<\mathrm{t} 2<\ldots \ldots$.tn.

$$
X_{i}=\ln \left(t_{i}-\gamma\right)
$$

When the number of samples is less than 20, the cumulative failure probability can be calculated by using the median rank,

$$
F\left(t_{i}\right)=\frac{i-0.3}{n+0.4}(i=1,2 \ldots, n)
$$

Or mean rank,

$$
F\left(t_{i}\right)=\frac{i}{n+1}(i=1,2 \ldots, n)
$$

When the number of samples is greater than 20 , the cumulative failure probability is calculated by the related $F\left(t_{i}\right)$.

$$
F\left(t_{i}\right)=\frac{i}{n+1}(i=1,2 \ldots, n)
$$

Mean rank formula is used here.

$$
\mathrm{Y}_{\mathrm{i}}=\ln \ln \left[\frac{1}{1-\mathrm{F}\left(\mathrm{t}_{\mathrm{i}}\right)}\right]=\ln \ln \left[\frac{1}{1-\mathrm{i} / \mathrm{n}+1}\right]
$$

Establishing equation of straight line. Through the parameter estimation of $a, b$ using least square method, obtained the parameters of Weibull distribution. The principle is to make the sun of squares of the deviation $\left(y_{i}-Y_{i}\right)$ of the measured value and the calculated value minimum as the optimization criterion.

$$
\begin{aligned}
& \mathrm{Q}=\sum\left(\mathrm{y}_{\mathrm{i}}-\mathrm{Y}_{\mathrm{i}}\right)^{2}=\sum\left(\mathrm{y}_{\mathrm{i}}-\mathrm{bx}_{\mathrm{i}}-\mathrm{a}\right)^{2} \\
& \mathrm{Q}=\sum\left(\mathrm{y}_{\mathrm{i}}-\mathrm{Y}_{\mathrm{i}}\right)^{2}=\sum\left(\mathrm{y}_{\mathrm{i}}-\mathrm{bx_{i }}-\mathrm{a}\right)^{2}
\end{aligned}
$$

Using the least square method to obtain the optimal solution of the linear coefficient estimation.

$$
\left\{\begin{array}{l}
\frac{\partial \mathrm{Q}}{\partial \mathrm{a}}=-2 \sum_{\mathrm{i}=1}^{\mathrm{n}}\left(\mathrm{y}_{\mathrm{i}}-\mathrm{bx}_{\mathrm{i}}-\mathrm{a}\right) \mathrm{x}_{\mathrm{i}}=0 \\
\frac{\partial \mathrm{Q}}{\partial \mathrm{b}}=-2 \sum_{\mathrm{i}=1}^{\mathrm{n}}\left(\mathrm{y}_{\mathrm{i}}-\mathrm{bx}_{\mathrm{i}}-\mathrm{a}\right)=0
\end{array}\right.
$$

The answer is:

$$
\left\{\begin{array}{c}
\mathrm{b}=\left(\sum_{\mathrm{i}=1}^{\mathrm{n}} \mathrm{x}_{\mathrm{i}} \mathrm{y}_{\mathrm{i}}-\mathrm{n} \overline{\mathrm{xy}}\right) /\left(\sum_{\mathrm{i}=1}^{\mathrm{n}} \mathrm{x}_{\mathrm{i}}^{2}-\mathrm{n} \overline{\mathrm{x}}^{2}\right) \\
\mathrm{a}=\overline{\mathrm{y}}-\overline{\mathrm{x}} \mathrm{b}
\end{array}\right.
$$

Using SPSS to calculate the parameters of the estimated value and obtain the failure distribution model, density function, failure rate function.

\section{Establishment for parts demand model}

On the basis of the statistical an analysing of the vehicle parts and determining the distribution of failure, forecasting the demand of spare parts is a practical method with strong feasibility. According to the sales data of the components of the same product, the life distribution model is obtained, which can calculate the failure probability and failure time of each component. Based on prediction sold parts demand quantity and demand cycle, not only can improve the efficiency of inventory stocking, and can be accurate to distribution, to streamline the cost saving resources, and service guarantee timeliness.

According to the failure rule, the failure rate function is obtained, and then the fault number is obtained from the failure rate and the sales volume. For mileage failure, according to the relationship between time and mileage, change the mileage to the time in the model, then the relationship between fault number and duration of using is obtained. Then calculate the failure of each time period, get the demand for spare parts.

Failure rate function

$$
\lambda(\mathrm{t})=\frac{\mathrm{f}(\mathrm{t})}{\mathrm{R}(\mathrm{t})}=\frac{\mathrm{m}(\mathrm{t}-\gamma)^{\mathrm{m}-1}}{\mathrm{t}_{0}}
$$

Preliminary fault number model

$$
X=\int_{0}^{T} \lambda(t) N(t) d t
$$

where $N(t)$ indicates the number of remaining parts

If it is according to the statistics of the month, then, integration can be converted into summation formula.

$$
X=\sum_{1}^{k} \lambda\left(t_{i}\right) N\left(t_{i}\right)
$$

\section{Case illustration and analysis}

\subsection{Solution and analysis of failure distribution model of injection pump}

The data of this paper is to extract the fault data from the second half of 2012 from the database of the task group. By censoring, the fault mileage L divided into 6 groups. 
Table1 Fault mileage and frequency

\begin{tabular}{|c|c|c|c|c|c|}
\hline $\begin{array}{l}\text { Group } \\
\text { number }\end{array}$ & $\begin{array}{l}\text { Interval } \\
\text { lower } \\
\text { limit } \\
/ \mathrm{km}\end{array}$ & $\begin{array}{l}\text { Interval } \\
\text { upper } \\
\text { limit } \\
/ \mathrm{km}\end{array}$ & $\begin{array}{l}\text { Group } \\
\text { mid- } \\
\text { value } \\
/ \mathrm{km}\end{array}$ & $\begin{array}{l}\text { Frequ } \\
\text { ency } \\
\text { /time }\end{array}$ & Frequency \\
\hline 1 & 250 & 21663 & 10956.5 & 19 & $\begin{array}{l}0.3653846 \\
15\end{array}$ \\
\hline 2 & 21663 & 43076 & 32369.5 & 11 & $\begin{array}{l}0.2115384 \\
62\end{array}$ \\
\hline 3 & 43076 & 64489 & 53782.5 & 9 & $\begin{array}{l}0.1730769 \\
23\end{array}$ \\
\hline 4 & 64489 & 85902 & 75195.5 & 7 & $\begin{array}{l}0.1346153 \\
85\end{array}$ \\
\hline 5 & 85902 & 107315 & 96608.5 & 4 & $\begin{array}{l}0.0769230 \\
77\end{array}$ \\
\hline 6 & 107315 & 128740 & $\begin{array}{l}118027 . \\
5\end{array}$ & 2 & $\begin{array}{l}0.0384615 \\
38\end{array}$ \\
\hline
\end{tabular}

According to the previous section established the Weibull distribution model, the parameters were calculated as: $b=0.790, \quad a=-8.468$

The correlation coefficient is: $\mathrm{R}^{2}=0.968 \approx 1$ It is significantly correlated.

linear equation is $\mathrm{Y}=0.790 \mathrm{X}-8.468$

Parameter

$$
\left\{\begin{array}{c}
m=0.790 \\
t_{0}=e^{8.468}=4759.99
\end{array}\right.
$$

Failure distribution model

$$
\mathrm{F}(\mathrm{t})=1-\exp \left[-\frac{\mathrm{t}^{0.790}}{4759.99}\right]
$$

Density function

$$
f(t)=\frac{0.79}{4759.99} t^{-0.21} e^{-\frac{t}{4759.99}}
$$

Failure rate function

$$
\lambda(t)=\frac{f(t)}{R(t)}=\frac{m(t-\gamma)^{m-1}}{t_{0}}=\frac{0.79 t^{-0.21}}{4759.99}
$$

According to the model, the probability density function of fault distance is plotted, and the density function curve and the failure rate curve are plotted by Matlab.

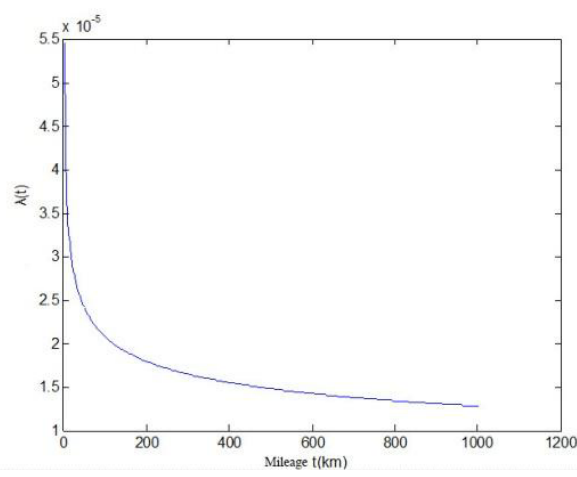

Figure 1 The failure rate curve.

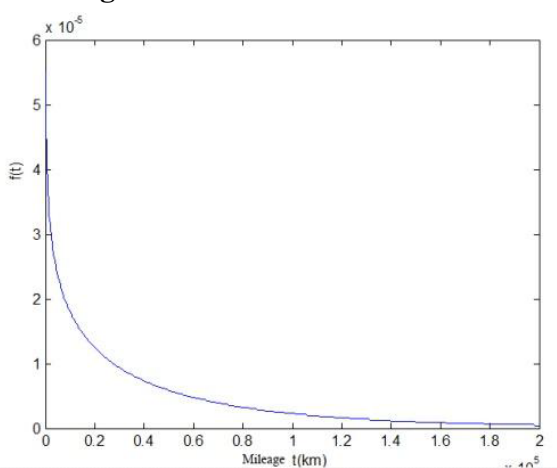

Figure 2 The probability density function curve.

It can be seen that the position parameter $\mathrm{m}<1$, which belongs to the early fault period. According to Figure 1, failure rate curve is monotonically decreasing, which belongs to the early fault type.

The mean time between failure(MTBF) of the fuel injection pump is:

$$
E(T)=M T B F=\int_{0}^{+\infty} R(t) d t=\int_{0}^{+\infty} t f(t) d t=\eta \Gamma\left(1+\frac{1}{m}\right)
$$

$$
\Gamma(x)=\int_{0}^{+\infty} t^{x-1} e^{-t} d t
$$

Using MATLAB to solve this integral, then

$$
\mathrm{MTBF}=\int_{0}^{+\infty} \mathrm{tf}(\mathrm{t}) \mathrm{dt}=31648(\mathrm{~km})
$$

Assuming that the average speed is $80 \mathrm{~km} / \mathrm{h}$, convert the number of kilometers to time, then

$\mathrm{MTBF}=395.6(\mathrm{~h})$

The mean time to repair(MTTR) can be obtained by observations as follows, assuming repair after 3 working days to repair, then

$$
\operatorname{MTTR}=\frac{1}{N_{o}} \sum_{i=1}^{n} t M i=24(\mathrm{~h})
$$

The availability $(\mathrm{A})$ is

$$
A=\frac{M T B F}{M T B F+M T T R}=0.942
$$


Failure rate function of fuel injection pump

$$
\lambda(t)=\frac{f(t)}{R(t)}=\frac{m(t-\gamma)^{m-1}}{t_{0}}=\frac{0.79 t^{-0.21}}{4759.99}
$$

In order to facilitate the demonstration, it is assumed that: diesel engine is used on the bus, the daily mileage is $156 \mathrm{~km} / \mathrm{d}, 30$ days per month, sales is 1000 , then calculated the demand for each month respectively.

Set the lower limit is 0 , the upper limit is 4680,put the failure rate function into it, using matlab to solve, after calculation, the failure number of the fuel injection pump in January is obtained.

$$
\mathrm{X} 1=167
$$

The result is the failure number within one month under the condition of theoretical state. In practice, many other factors need to be considered in order to make more accurate decision, such as environmental factors, seasonal factors and so on. In addition, according to this formula can calculate the failure number in each month. The data is shown in Fig. 3

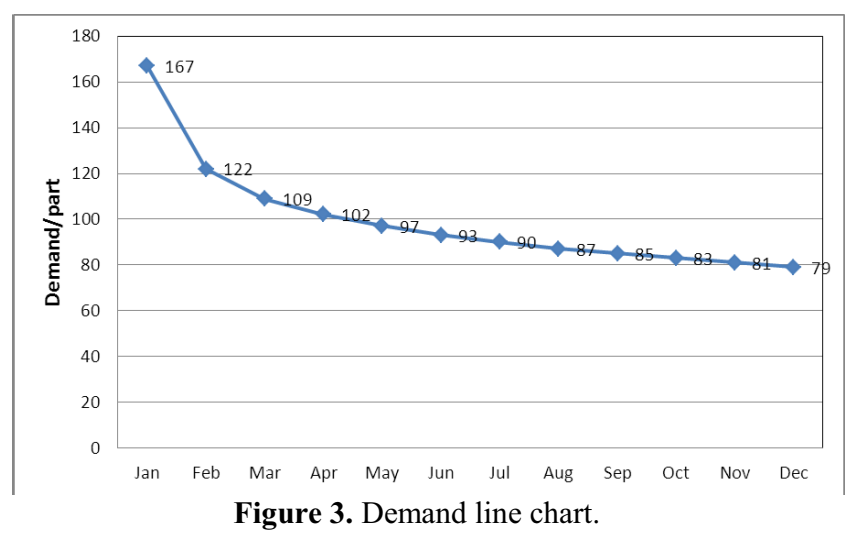

As can be seen from Fig. 3, the fuel injection pump which is in the early fault period, since the sales, the number of failures per month is decreased, the demand is also gradually reduced, according to the demand forecasting model can get the monthly demand theoretically. By analyzing the failure rule of the parts, the life and failure rate of the components are obtained.
When the parts to wear out failure, guide distribution in advance.

\section{Conclusion}

According to the fuel injection pump of diesel engine failure distribution, the Weibull model is established. Using the uniform linear method to estimate the parameters, the model is solved, and the failure distribution model of the injection pump is established. Using the matlab curve fitting, we can see that the curve of failure rate is monotonically decreasing, which belongs to the early fault type. Based on the failure distribution model, the life index of spare parts is calculated, and then the parts distribution demand model is established, and the theoretical optimal stocking quantity of each month is calculated by the example of the fuel injection pump. This model can ahead of guidance distribution, to enhance emergency response speed, improve service levels and make distribution cycle plan, monthly distribution. When the failure number is a large quantity, it is helpful in making flexible distribution measures and the cost reduction.

\section{References}

1. W Weibull. A statistical distribution function of wide applicability [J]. Journal of Applied Mechanics, 18(3):293-297. (1951).

2. Abernethy R B. The new weibull handbook(5th edition) $[\mathrm{M}]$. North Palm Beach: Robert B: Abernethy, (2006).

3. Fang yuanhua, Fan zhendong, $\mathrm{Hu}$ changhua. Maximum Likelihood Optimization Estimation for Parameters of Reliability Life Distribution by GA [J]. AEROSPACE SHANGHA I, (2):50-53.(2006).

4. Mann N R. Warranty periods based on three ordered sample observations from a Weibull population [J]. IEEE Transactions on Reliability, 19(4):167171.( 1970). 